\title{
A Unified Bond Graph Modeling Approach for the Ejection Phase of the Cardiovascular System
}

\author{
LUBNA CHUGHTAI*, VALI UDDIN**, BHAWANI SHANKAR CHOWDHRY***, AND QAISAR JAVAID**** \\ RECEIVED ON 20.01.2016 ACCEPTED ON 16.02.2016
}

\begin{abstract}
In this paper the unified Bond Graph model of the left ventricle ejection phase is presented, simulated and validated. The integro-differential and ordinary differential equations obtained from the bond graph models are simulated using ODE45 (Ordinary Differential Equation Solver) on MATLAB and Simulink. The results, thus, obtained are compared with CVS (Cardiovascular System) physiological data present in Simbiosys (a software for simulating biological systems) and also with the CVS Wiggers diagram of heart cycle. As the cardiac activity is a multi domain process that includes mechanical, hydraulic, chemical and electrical events; therefore, for modeling such systems a unified modeling approach is needed. In this paper the unified Bond Graph model of the left ventricle ejection phase is proposed. The Bond Graph conventionalism approach is a graphical method principally powerful to portray multienergy systems, as it is formulated on the portrayal of power exchanges. The model takes into account a simplified description of the left ventricle which is close to the medical investigation promoting the apperception and the dialogue between engineers and physiologists.
\end{abstract}

Key Words: Biomedical Engineering, Cardiography, Closed Loop System, Modeling, Bond Graph.

\section{INTRODUCTION}

W

ith the advancement of the scientific research, heart transplantation is now been endorsed as the suitable salutary treatment for patients with last phase CHF (Congestive Heart Failure) [1]. CHF is a condition in which the ventricle fails to pump the required amount of blood. However, in most cases the patients have to wait so long that many of these sufferers die waiting for the availability of donors for heart transplantation. Henceforth, the medical community has assigned significant stress on the prominence of mechanical circulatory assist device that can surrogate or strengthen the operation of the natural heart while the person is awaiting for heart transplant [2].The AHPs (Artificial Heart Pumps) can either be used as a total artificial heart replacing both ventricles or as a left ventricular assist device to aid the failed left ventricle. The left ventricle is responsible for ejecting blood through whole the body therefore its workload is prodigious than any other heart segment. This is the reason that nearly more than $3 / 4$ and $75 \%$ of the heart failures are caused by failure of left ventricle. In order to do better designing of controller for ventricular assist device it is very important to have a proper model of heart which is not only simple but also captures the complete behavior.

\footnotetext{
* National University of Sciences \& Technology, Islamabad.

** Hamdard University, Madinatul Hikmat, Karachi.

*** Faculty of Electrical, Electronic \& Computer Engineering, Mehran University of Engineering and Technology, Jamshoro.

**** Department of Computer Science \& Software Engineering, International Islamic University, Islamabad.
} 
CVS is a very complex system which includes interaction of several subsystems like the heart and the circulatory system. Further, the autonomous peripheral sense organs are responsible for the regulation of the CVS and influence its function through baroreflex mechanism. Baroreflex or baroreceptor reflex is the natural negative feedback loop to keep the pressure constant [3]. Therefore, the model of the CVS should describe the behavior of each subsystem and takes into account the interaction between them. Furthermore, several energy domains describe the CVS activity; there are mechanical, hydraulic, chemical and electrical events. To take into account all these characteristics, the bond graph seems to provide a unified approach. In this research paper the left heart is modeled for ejection phase using bond graph unified modeling. Each blood vessel is characterized by a parallel capacitance and resistance. The capacitance represents elasticity of the vessel wall, resistance enacts the vessel opposition to the blood flow and inertance portray the inertial blood movement. These three elements are linked by bond graph 0 and 1 junctions. The 0-Junction corresponds to same blood pressure and 1-Junction for the same blood flow [4]. The important feature that the bond graph technique provides is that of sub division or reticulation of the network. This is equivalent to system decomposition or disaggregation and facilitates hierarchical modeling concepts. The CVS Physiological model is discussed in section 2.1. The main contribution of the author is firstly to develop a Bond Graph for the $4^{\text {th }}$ order CVS system, secondly is to develop a time varying state space representation from the Bond Graph Lagrangian equations, thirdly developing an algorithm in MATLAB for simulation.

\section{MATERIALS AND METHOD}

\subsection{Cardiovascular System}

The basic heart and main CVS loops are sketched below in Figs.1-2. The fundamental components of a CVS are heart, blood and blood vessels (arteries and veins). The CVS is a closed loop system, divided into two distinct paths. One is pulmonary circulation which is a closed circuit starting from right ventricle to the lungs and then back to left atrium. [5]. The second is a systemic circulation which is again a close circuit starting from left ventricle to whole of the body vessels and again back to right atrium [6].

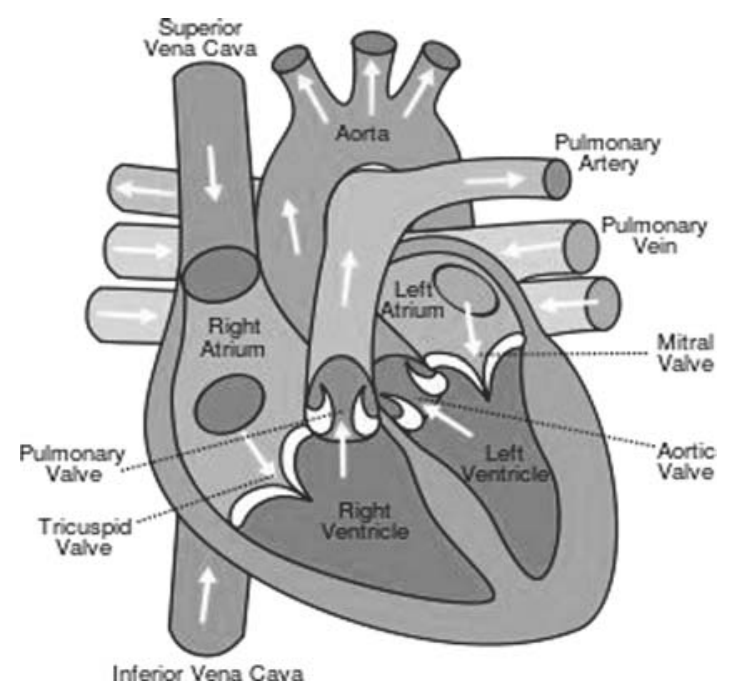

FIG. 1. HEART MODEL [1]

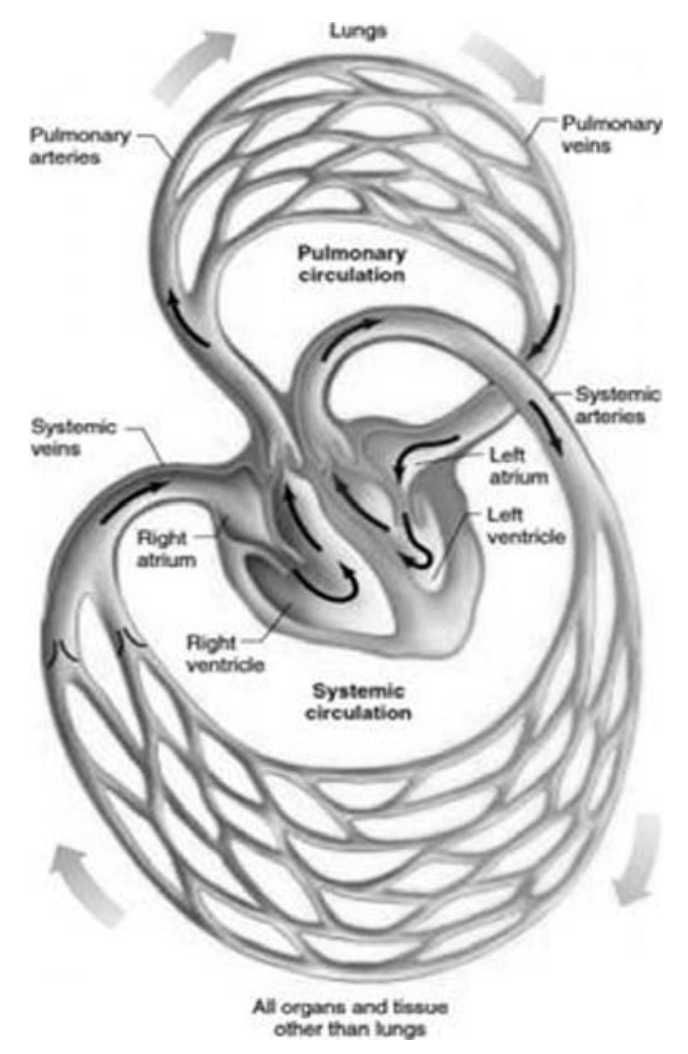

FIG. 2. THE CARDIOVASCULAR LOOP [5] 
The heart is divided into four portions, left and right atrium and left and right ventricle. The deoxygenated blood from the body returned to the right atrium and passes to the right ventricle from where it is pumped through the pulmonary artery to the lungs for exchange of gases. The oxygenated blood then enters the heart through the left atrium which is then passed to the left ventricle from where it is pumped to the systemic circuit. The systemic circulation is much lengthy than the pulmonary one and combat noticeable more resistance. As the left ventricle handles longer path, it is more elastic than the right ventricle. This elasticity makes it more vigor to pump the blood at higher pressure [6]. Because of the disparate responsibility and different work load of the two circulation paths, the activation function of the left ventricle pumps nearly more than four times of the right ventricle contraction.

There are two types of valves present in heart, Atrioventricular Valves and Semi Lunar Valves. Atrioventricular valves, as its name describes, are between atria and ventricle, therefore, there are two such valves. The one between the right atrium and right ventricle known as Tricuspid valve while the other one between left atrium and left ventricle known as Mitral valve. The Semilunar valves are between ventricles and main arteries. The one between right ventricle and pulmonary artery is known as Pulmonary Valve and the valve between left ventricle and main systemic aorta is known as Aortic Valve. All these valves allow unidirectional flow of blood.

There are basic two phases of heart operation, Systolic (ejection) and Diastolic (relaxation) phase. The Cardiovascular System is a very enigmatic system and is very challenging to model mathematically [6]. Diversified lusty models of manifold extent of intricacy have emerged in the past few years but the basic of all such mathematical model is same i.e. Otto Frank Windkessel model who laid the foundation of heart pump model at the outset of twentieth century proposed that the aorta could be portrayed by a lumped dilatable section and a constituent resistance. In an electrical analog, it can be modeled as a combination of capacitor and resistor is parallel. The basic analogy between Cardiovascular Physiological and Electrical system is mentioned in Table 1.

In the succeeding research, classical two element Windkessel model has been extended to account for the impedance of arterial load and blood inertia. This subsequential research emerged as extended third and fourth element Windkessel model [7]. In this research, a $4^{\text {th }}$ order

TABLE 1. ELECTRICAL EQUIVALENTS OF PHYSIOLOGICAL PARAMETERS

\begin{tabular}{|c|c|}
\hline Cardiovascular Physiological Parameter & Electrical Equivalent \\
\hline Blood Flow (F) & Electric Current (I) \\
\hline Pressure $(\mathrm{P})$ & Potential (V) \\
\hline Vascular Resistance $\mathrm{R}_{\mathrm{c}}=\mathrm{P} / \mathrm{F}$ & Resistance $\mathrm{R}_{\mathrm{e}}=\mathrm{V} / 1$ \\
\hline $\begin{array}{l}\text { Flow through the vessel Compliance; } \mathrm{F}_{\mathrm{i}}=\mathrm{Cc} \mathrm{dv} / \mathrm{dt} \\
\text { Where } \mathrm{F}_{\mathrm{i}} \text { is Inflow to vessel, } \mathrm{C}_{\mathrm{c}} \text { is vessel compliance, and } \mathrm{dv} / \mathrm{dt} \text { is Change } \\
\text { in pressure inside vessel }\end{array}$ & $\begin{array}{l}\text { Flow through capacitor; } \mathrm{I}=\mathrm{C}_{\mathrm{e}} \mathrm{dv} / \mathrm{dt} \\
\text { Where } \mathrm{C}_{\mathrm{e}} \text { is the electrical capacitance }\end{array}$ \\
\hline Blood Inertia $\mathrm{P}=\mathrm{L}_{\mathrm{c}} \mathrm{dF} / \mathrm{dt}$ & Inductance $\mathrm{V}=\mathrm{L}_{\mathrm{e}} \mathrm{d} \mathrm{I} / \mathrm{dt}$ \\
\hline $\begin{array}{l}\text { Valves: The atrioventricular and Semi lunar valves are unidirectional i.e. they } \\
\text { force the blood to flow in one direction. It always opposes the flow until the } \\
\text { pressure difference is higher than a certain critical pressure P critical. } \\
\qquad F=\left\{\begin{array}{rll}O & \text { if } & P\langle\text { Pcritical } \\
P / R_{c} & \text { if } & P \geq \text { Pcritical }\end{array}\right.\end{array}$ & 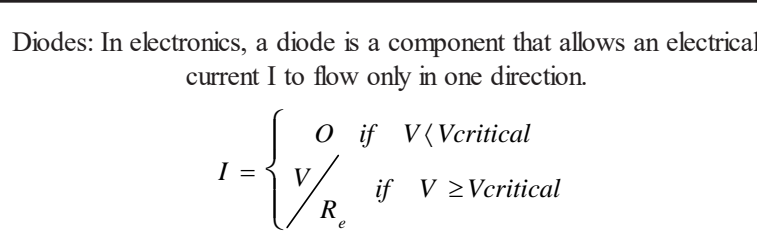 \\
\hline
\end{tabular}

Mehran University Research Journal of Engineering \& Technology, Volume 35, No. 3, July, 2016 [p-ISSN: 0254-7821, e-ISSN: 2413-7219] 
lumped parameter Windkessel model as shown in circuit Fig. 3 has been selected. This model is selected from Shao and Chen work [5], which can reflect the left ventricular hemodynamic of the heart. The Table 2 illustrates the analogy of Electrical model parameter selected in the model with their Physiological meanings and numerical values.

Model Parameters are described in Table 2.

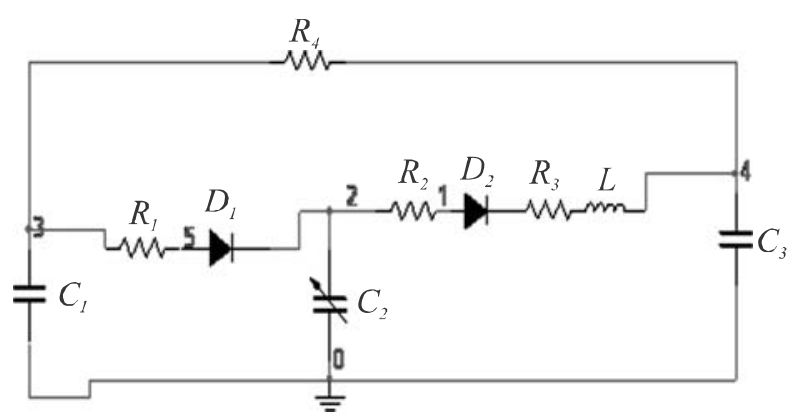

FIG. 3. LUMPED HEART MODEL [9]

TABLE 2. MODEL PARAMETERS

\begin{tabular}{|c|c|c|}
\hline Parameter & Physiological meaning & Value \\
\hline C1 & Left atrial compliance & $4.4 \mathrm{ml} / \mathrm{mm} \mathrm{Hg}$ \\
\hline C2(t) & $\begin{array}{c}\text { Time varying left ventricular } \\
\text { compliance }\end{array}$ & Time varying \\
\hline C2 & Systemic compliance & $1.333 \mathrm{ml} / \mathrm{mm} \mathrm{Hg}$ \\
\hline L & Inertance of blood in aorta & $0.0005 \mathrm{~mm} \mathrm{Hg.s} 2 / \mathrm{ml}$ \\
\hline R1 & Mitral valve resistance & $0.0050 \mathrm{~mm} \mathrm{Hg.s} / \mathrm{ml}$ \\
\hline R2 & Aortic valve resistance & $0.0010 \mathrm{~mm} \mathrm{Hg.s} / \mathrm{ml}$ \\
\hline R3 & Characteristic resistance & $0.0398 \mathrm{~mm} \mathrm{Hg.s} / \mathrm{ml}$ \\
\hline R4 & Systemic vascular resistance & $1.00 \mathrm{~mm} \mathrm{Hg.s} / \mathrm{ml}$ \\
\hline D1 & Mitral valve & Ideal switch \\
\hline D2 & Aortic valve & Ideal switch \\
\hline
\end{tabular}

\subsection{Selection of State Variables and their Physiological Meanings}

In the selected model there are four energy storage elements, therefore, there will be four state variables. The variables selected with their Engineering aspect and Physiological meanings are expressed in Table 3.

\subsection{Left Ventricular Elastance}

The heart may be deliberated as a pump getting blood from a low pressure network and boosting it to a high pressure system [6]. The methodology is liable for generating wall stress and hence the pressure on left ventricle is due to the compression of the Myocardial Fibers. In this model, the left ventricle is characterized as a Time Varying Capacitor, which is the reciprocal to the Elastance function. The approach of Elastance was first designated for blood vessels by associating incremental cross section area or volume and transmural pressure. Liang, et. al. [8] was the first to ratify a compliance description for a dynamic heart.

The compliance of ventricle can be delineated at any point as the rate of change of volume with respect to change in pressure i.e.

$$
\begin{aligned}
& C=\frac{d v}{d p} \\
& E=\frac{1}{C} ; E=\frac{d_{p}}{d_{v}}
\end{aligned}
$$

TABLE 3. STATE VARIABLES

\begin{tabular}{|c|c|c|}
\hline Variable & Engineering Aspect & Physiological Meaning \\
\hline $\mathrm{x} 1(\mathrm{t})$ & (Voltage Across Capacitor-1) & LAP (Left Aatrial Pressure) \\
\hline $\mathrm{X} 2(\mathrm{t})$ & $\mathrm{VC} 2(\mathrm{t})$ (Variable Voltage Across Capacitor-2) & LVP(Left Ventricular Pressure) \\
\hline $\mathrm{X} 3(\mathrm{t})$ & $\mathrm{VC} 3$ (Voltage Across Capacitor-3) & AP (Aortic Pressure or Arterial Pressure) \\
\hline $\mathrm{X} 4(\mathrm{t})$ & $\mathrm{IL}($ Current through Inductor) & QA (Arterial Flow or Aortic Flow) \\
\hline
\end{tabular}


If capacitance is not varying, this equation becomes a linear relation. If integration is applied on 2.3.1, we obtain:

$\mathrm{V}=\mathrm{C}_{\mathrm{p}}+\mathrm{V}_{\mathrm{c}}$

If the compliance is time varying then:

$\mathrm{V}(\mathrm{t})=\mathrm{C}(\mathrm{t}) \mathrm{p}(\mathrm{t})+\mathrm{V}_{\mathrm{c}}(\mathrm{t})$

Combining Equations (1-4), the following relation is obtained:

$E(t)=\frac{p(t)}{V(t)-V_{d}}$

Left Ventricular Elastance $=\frac{\text { Left Ventricular Pressure }}{\text { Left Ventricular Volume }}$ nstressed Volume at Zero

There are different methods to find out the Elastance function, in this research paper double hill function has been used [9], which can be stated mathematically as:

$\mathrm{e}(\mathrm{t})=\left(\mathrm{e}_{\max }-\mathrm{e}_{\min }\right) \mathrm{E}_{\mathrm{n}}\left(\mathrm{t}_{\mathrm{n}}\right)-\mathrm{e}_{\text {min }}$

$E_{n}\left(t_{n}\right)=1.55\left[\frac{\left(\frac{t_{n}}{0.7}\right) 1.9}{1+\left(\frac{t_{n}}{0.7}\right) 1.9}\right]\left[\frac{1}{1+\left(\frac{t_{n}}{1.17}\right) 21.9}\right]$

Where, $\mathrm{t}_{\mathrm{n}}=\mathrm{t} / \mathrm{t}_{\text {max }}$ and $\mathrm{t}_{\text {max }}=0.2+0.15 \mathrm{t}_{\mathrm{c}} ; \mathrm{t}_{\mathrm{c}}$ is the Cardiac cycle interval, $\mathrm{t}_{\mathrm{c}}=60 / \mathrm{HR}, \mathrm{HR}$ is the heart rate taken as 75 $\mathrm{bpm}, \mathrm{e}_{\max }$ is the end systolic pressure, $\mathrm{e}_{\text {min }}$ is the diastolic pressure.

The linearity of the instantaneous pressure volume relation is very well discussed by Wolfgang [4]. He explored the work done by Sodum, Baan, Sprats and Park indicating the highly linear end systolic pressure volume relation.

\subsection{Phases of the Cardiac Cycle}

There are four phases of cardiac cycle, as summarized in Table 4.

\subsection{Model Equations for Ejection Phase}

During the systolic phase the left ventricle pumps the blood into the main arterial system. Since, there are four state variables; therefore, there will be four differential equations.

$\dot{x}(t)=A x(t)$

State space equation with physiological meaning

$\dot{x}_{1}(t)=-\frac{1}{C_{1} R_{4}} x_{1}(t)+\frac{1}{C_{1} R_{4}} x_{3}(t)$

Physiological meaning of equation

$$
\begin{aligned}
& \text { Left Atrium Pressure }=\frac{1}{\text { Left Atrial Compliance }}(L A P+A P) \\
& \begin{array}{c}
\times \\
\text { Systemic Resistance }
\end{array} \\
& \dot{x}_{1}(t)=-\frac{1}{C_{2}(t)} x_{4} \text { or } e_{l v}(t) x_{4}
\end{aligned}
$$

Physiological meaning of equation

LVP + Left Ventricular Elastance x Aortic Flow

TABLE 4. PHASES OF CARDIAC CYCLE

\begin{tabular}{|c|c|c|}
\hline No. & Phases & State of valve \\
\hline 1. & $\begin{array}{c}\text { Isovolumic } \\
\text { Contraction }\end{array}$ & $\begin{array}{c}\text { Both mitral and aortic valves closed; } \\
\text { and open. }\end{array}$ \\
\hline 2. & $\begin{array}{c}\text { Isovolumic } \\
\text { Relaxation }\end{array}$ & $\begin{array}{c}\text { Both mitral and aortic valve closed; } \\
\text { and open. }\end{array}$ \\
\hline 3. & Ejection & $\begin{array}{c}\text { Aortic open and Mitral valves closed } \\
\text { open and closed. }\end{array}$ \\
\hline 4. & Filling & $\begin{array}{c}\text { Mitral open and Aortic valves closed, } \\
\text { closed and open. }\end{array}$ \\
\hline
\end{tabular}


$\dot{x}_{3}(t)=-\frac{1}{R_{4} C_{3}} x_{1}(t)-\frac{X_{3}(t)}{R_{4} C_{3}}$

Physiological meaning of equation

$$
\begin{gathered}
\text { Derivative of the Systemic } \\
\begin{array}{c}
\text { Arterial Pressure } \\
\text { Systemic Resistance }
\end{array} \\
\begin{array}{c}
\times \\
\text { rterial Compliance }
\end{array}
\end{gathered}
$$

$\dot{\mathrm{x}}_{4}=-\frac{\mathrm{e}(\mathrm{t})}{\mathrm{L}} \times 2-\frac{1}{\mathrm{~L}} \times 3-\frac{\mathrm{R} 2+\mathrm{R} 3}{\mathrm{~L}} \times 4$

Physiological meaning of equation

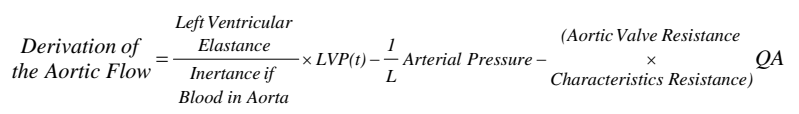

The state matrix will be

$$
\left[\begin{array}{c}
\dot{x}_{1}(t) \\
\dot{x}_{2}(t) \\
\dot{x}_{3}(t) \\
\dot{x}_{4}(t)
\end{array}\right]=\left[\begin{array}{cccc}
-\frac{1}{C_{1} R_{4}} & 0 & \frac{1}{C_{1} R_{4}} & 0 \\
0 & 0 & 0 & e_{l v} \\
\frac{1}{R_{4} C_{3}} & 0 & -\frac{1}{R_{4} C_{3}} & 0 \\
0 & \frac{e(t)}{L} & -\frac{1}{L} & \frac{-\left(R_{2}+R_{3}\right)}{L}
\end{array}\right]\left[\begin{array}{c}
x_{1} \\
x_{2} \\
x_{3} \\
x_{4}
\end{array}\right]
$$

\subsection{Bond Graph Modeling}

For the systems engrossing multiple energy domains, Bond Graph is a prudent modeling technique. The Bond Graph technique was firstly recognized by Paynter and later on further developed by Karnopp and Rosenberg. Bond Graph is a directed graph whose nodes designate subsystems and arrows indicate the transfer of energy between subsystems [7]. Multi domain feature is inbuilt in Bond Graph modeling. The Bond Graph may be used to model energy transformation across many energy domains including electrical, mechanical, hydraulic, thermal, magnetic and chemical. The Bond Graph takes into consideration both topological and computational structure of the multi domain system. BG handles with intermutual BG components such as Capacitance (C), Inertias (I), Resistance (R), Sources (Se,Sf), Gyrator (GY), Transformer (Tf) and Junctions $(0,1)$ to enact the system components and their behavior. The Bond Graph components can be classified as 1-ports, 2-ports and multiple port components. The 1-port components refer to $\{\mathrm{Se}, \mathrm{Sf}, \mathrm{I}, \mathrm{R}, \mathrm{C}\}$, the 2-ports components refer to $\{\mathrm{Tf}$, $\mathrm{GY}$ \} and the multiple ports components refer to BG junction $(0,1)$. These Bond Graph different elements are linked by bonds to model the behavior of the overall physical system [7]. An effort and flow variable is assigned to each bond illustrating signals of the elements. The 0 junction corresponds to the same voltages with sum of all current zero.

For 0junction $\rightarrow e_{1}=e_{2}=e_{3}$ (obeys KVL) and $f_{1}+f_{2}+f_{3}=0$

For 1 junction $\rightarrow e_{1}+e_{2}+e_{3}=0$ (obeys KCL) and $f_{1}=f_{2}=f_{3}$

Added to the generalized modeling competence, the Bond Graph modeling also implement a concept called the Causality for deriving equation from graph. Bond Graphs have an apprehension anticipation of causality, which indicates the effort and flow directions. Basically causality is a uniformity of elements cause and effect relationship. There is a stroke marked at the end of every bond indicating the direction of effort and flow signal. [7]. Table 5 shows the basic elements of the Bond Graph. The contribution of Bond Graph method in Physiology is briefly discussed in section 2.7.

\subsection{Bond Graph Modeling in Physiology}

The Bond Graph modeling technique is a definite graphical gizmo depiction for apprehending the simple energy framework of systems by system elements which activate, store, absorb, transmit or transmute energy. In this study the Bond Graph will represent the flow of blood in the CVS. This study will demonstrate that Bond Graph is a conclusive tool to model the physiological system. The compact nature of Bond Graph also makes them ideal for representing the fluid flow, which is just a particular 
form of energy transport [3]. Using the Bond Graph, just by using basic sets of ideal elements the models of electrical, magnetic, mechanical, hydraulic, pneumatic, thermal and other systems can easily be constructed [12].There are diversified applications of the Bond Graph especially in industries; however, some work on the application of Bond Graph in physiology already exist, such as, the designing of the controller for Muscle Relaxant Anesthesia using Bond Graph by Linken, et. al. [13], the modeling of Musculoskeletal Structure by Wojeik [9], the models of Vascular System by Diaz-Insua and Delgado [12] and Olsen, et. al. [14].

\subsection{Bond Graph Model for Ejection Phase}

For formulating the Bond Graph from Fig. 3, some basic rules of Bond Graph construction are considered taken from Borutzky 2010. In a bond Graph method, a physical System can be represented by symbols and lines, identifying the power flow path. The lumped parameter elements such as resistance, capacitance and resistance are inter connected in an energy conserving manner by bonds and junctions resulting in a rectangle structure. There are four basic variables in Bond Graph; effort, flow, time integral of effort and time integral of flow i.e. $\mathrm{P}=$ effort $\mathrm{x}$ flow. The power is always a generalized coordinate to model the complete systems residing in several energy domains. No doubt the efforts and flow have different interpretation for different physical state as given in Table 6 .

R-Element: R element corresponds to the analogous passive elements such as electrical resistor or mechanical damper symbol for resistor is:

$$
\underset{f}{\stackrel{e}{\longrightarrow}} R
$$

The half arrow represents the direction of flow.

C-Element: C-Element corresponds to a device that stores and give up energy without loss. It can also be stated as an element that relates effort to the generalized displacement or time integral of flow: The bond graph representation of C-Element is:

$$
\underset{f}{\stackrel{e}{\longrightarrow}} C
$$

TABLE 6. EFFORT AND FLOW IN DIFFERENT DOMAINS

\begin{tabular}{|c|c|c|}
\hline System Domain & Effort (e) & Flow (f) \\
\hline Hydraulic & Pressure & Volume flow rate \\
\hline Electrical & Voltage & Current \\
\hline Mechanical Translational & Force & Velocity \\
\hline Mechanical rotational & Torque & Angular Velocity \\
\hline
\end{tabular}

\begin{tabular}{|c|c|c|}
\hline Element & Effort Causal & Flow Causal \\
\hline Resistor & $\underset{f}{e} R: R f=\frac{e}{R}$ & $\underset{f}{\stackrel{e}{\longrightarrow}} R: R e-f \cdot R$ \\
\hline Capacitor & $\underset{f}{e} C: C f=C \frac{e}{R}$ & $\underset{f}{e} C: C e=\int \frac{f}{C} \cdot d t$ \\
\hline Inductor & $\underset{f}{e} I: I f=\int \frac{e}{L} \cdot d t$ & $\underset{f}{e} I: L e=L \frac{d f}{d t}$ \\
\hline Source & $S_{e}=V \underset{f}{\rightarrow} e=V$ & $S_{f}=I \underset{f}{\rightarrow} f=I$ \\
\hline
\end{tabular}

TABLE 5. BASIC BOND GRAPH ELEMENTS

Mehran University Research Journal of Engineering \& Technology, Volume 35, No. 3, July, 2016 [p-ISSN: 0254-7821, e-ISSN: 2413-7219] 
Here flow in the cause and deformation (effort), the consequence. In a capacitor the charge accumulated on the plates $(\mathrm{Q})$ is defined as:

$Q=\int_{-\infty}^{+} i d t$

or

$e=\frac{1}{c} \int_{-\infty}^{+} i d t$

I- Elements: The inertial element is used to model inductance or inertial effort symbolically, it is represented as:

$i=L^{-1} \int_{-\infty}^{+} e d t \quad \underset{f}{\stackrel{e}{\longrightarrow}} 1$

Causality

Causality established the cause and effect relationship. The selected causality is generally indicated by cross bar or causal bar at the end to which the effort receiver is connected (Marwan [11]).

In Bond Graphs the flow of energy (in this case flow of blood) between elements are expressed as half arrows drawn at the end of each bond segment The two variables; Effort and Flow associated with each bond define the cause-effect relationship. The linkage of elements such as artery to the arterioles and then to venules and veins are specified by 0 (parallel) and 1(series) junctions of Bond Graph. Based on Table 5 the Bond Graph for ejection phase is shown in Fig. 4.

Assigning State Variables: The Bond Graph for the ejection phase of the model is shown in Fig. 4. For deriving equations from bond Graph, the energy storage and coenergy state variables must be firstly defined; $q$ and $p$ are the energy storage state variables. The physiological meaning of energy storage state variables is as follows:

$\dot{q}_{2}$ Is the derivative of charge through left atrium or the flow through the left atrium.

$\dot{q}_{7}$ Time varying flow through the left ventricle.

$\dot{q}_{14}$ Flow through the systemic aorta.

$\dot{p}_{12}$ Pressure across the inertial element of left systemic aorta.

The co-energy state variable are:

$\mathrm{e} \rightarrow$ voltage across the element

$\mathrm{f} \rightarrow$ through the element.

$\mathrm{e}_{2} \rightarrow$ pressure across the left atrium

$\mathrm{e}_{3} \rightarrow$ pressure across the systemic artery

$\mathrm{e}_{4} \rightarrow$ pressure across the mitral value

$\mathrm{e}_{7} \rightarrow$ pressure across the left ventricle

Bond Graph for the Left Ventricle Ejection Phase

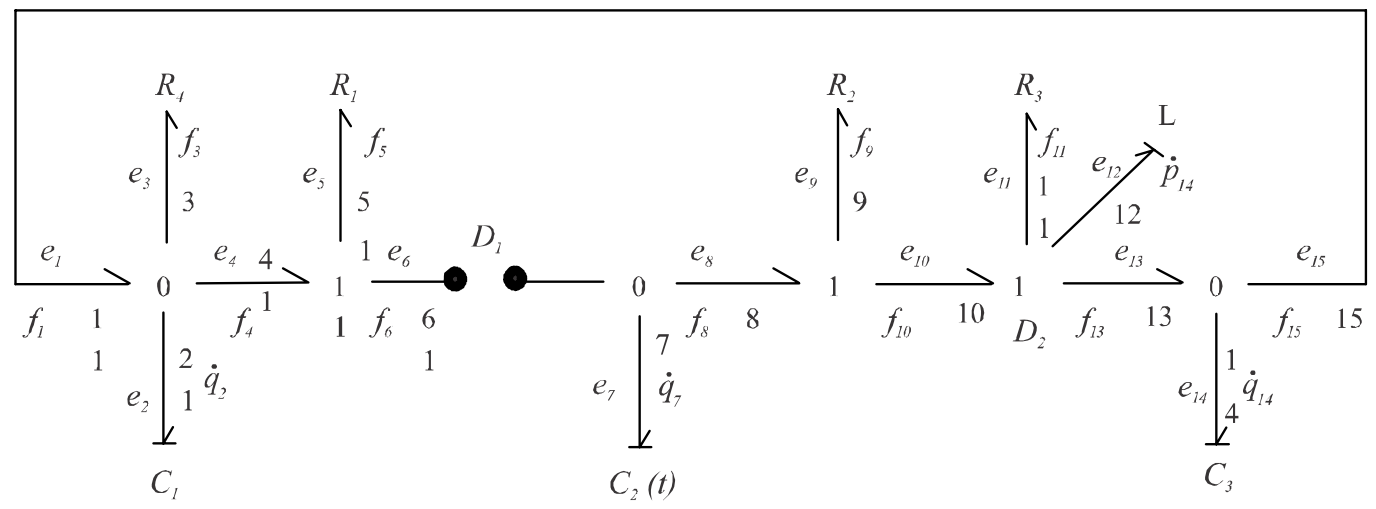

FIG. 4. BOND GRAPH OF THE LEFT VENTRICLE 
$\mathrm{e}_{9} \rightarrow$ pressure across the Aortic valve

$\mathrm{e}_{14} \rightarrow$ pressure across the systemic aorta

$\mathrm{f}_{1} \rightarrow$ flow through left atrium

$\mathrm{f}_{5} \rightarrow$ flow through mitral value

$\mathrm{f}_{9} \rightarrow$ flow through left ventricle

$\mathrm{f}_{11} \rightarrow$ flow through aortic valve

$\mathrm{f}_{12} \rightarrow$ flow through left inertial element

$\mathrm{f}_{15} \rightarrow$ flow through systemic variable artery

Here we have;

$e_{2}=\frac{1}{C_{1}} q_{2}$

For 0 junction '! $\mathrm{e}_{1}=\mathrm{e}_{2}=\mathrm{e}_{3}$ (obeys KVL) and $\mathrm{f}_{1}+\mathrm{f}_{2}+\mathrm{f}_{3}=0$

For 1 junction '! $\mathrm{e}_{1}+\mathrm{e}_{2}+\mathrm{e}_{3}$ (obeys KVL) and $\mathrm{f}_{1}+\mathrm{f}_{2}+\mathrm{f}_{3}$

Based on this explanation, now let us find the equation for state space. Using the 0 and 1 junction rules, the equations for all the state variables can be easily derived. Primarily, derive the $\dot{q}_{2}$, which is the flow through left atrial compliance. As it is zero junction, the sum of flow will be equal to zero and the sum of effect will be same.

$f_{1}=\dot{q}_{2}+f_{3}+f_{4}$

$\dot{q}_{2}=f_{1}-f_{3}\left(f_{4}=0\right.$ as MV is open $)$

$f_{3}=\frac{e_{3}}{R_{4}} ; f_{1}=\frac{1}{L} p_{11}-\frac{e_{14}}{R_{4}}$

$\dot{q}_{2}=-\frac{1}{C_{3} R_{4}} q_{14}+\frac{1}{C_{1} R_{4}} q_{2}+\frac{1}{L} P_{11}$

Now find out the time varying flow through left ventricle $\dot{q}_{7}$

$f_{6}=\dot{q}_{7}+f_{8}$

$\dot{q}_{7}=-f_{8}=-f_{9}$
$\dot{q}_{7}=-\frac{e_{7}}{R_{2}} q_{7}$

$\dot{q}_{7}=-\frac{1}{C_{1}(t) R_{2}} q_{7}$

$\dot{q}_{7}=-\frac{e_{l v}}{R_{2}} q_{7}$

$\dot{q}_{14}$ flow through the systemic aorta.

$f_{13}=\dot{q}_{14}+f_{1}$

$\dot{q}_{14}=f_{13}-f_{1}$

$\dot{q}_{14}=-\frac{1}{C_{1} R_{4}} q_{2}+\frac{1}{C_{3} R_{2}} q_{14}-\frac{1}{L} p_{12}$

Now the $\dot{p}_{12}$ Pressure across the inertial element of left systemic aorta can be calculated:

$e_{10}=e_{11}+\dot{p}_{12}+e_{13}$

$\dot{p}_{12}=e_{10}-e_{11}-e_{13}$

$e_{13}=e_{14}=\frac{1}{C_{3}} q_{14}$

$e_{11}=f_{12} R_{3}=\frac{1}{L} p_{11} R_{3}$

$e_{10}=e_{8}-e_{9}$

$e_{10}=e_{7}-f_{12} R_{2}$

$e_{10}=\frac{1}{C_{2}(t)} q_{7}-\frac{1}{L} p_{12} R_{2}$

$\dot{p}_{12}=\frac{1}{C_{2}(t)} q_{7}-\frac{1}{L} p_{12} R_{2}-\frac{1}{L} p_{12} R_{3}-\frac{1}{C_{3}} q_{14}$

$\dot{p}_{12}=\frac{1}{C_{2}(t)} q_{7}-\left(\frac{R_{2}+R_{3}}{L}\right) p_{12}-\frac{1}{C_{3}} q_{14}$ 
The State Space form is:

$$
\left[\begin{array}{c}
\dot{q}_{2} \\
\dot{q}_{7} \\
q_{14} \\
p_{12}
\end{array}\right]=\left[\begin{array}{cccc}
\frac{1}{C_{1} R_{4}} & 0 & -\frac{1}{C_{1} R_{4}} & 1 / L \\
0 & e_{l v} / R_{2} & 0 & 0 \\
-\frac{1}{C_{1} R_{4}} & 0 & \frac{1}{C_{3} R_{4}} & -1 / L \\
0 & e_{l v} & 1 / C_{3} & \frac{-\left(R_{2}+R_{3}\right)}{L}
\end{array}\right]\left[\begin{array}{c}
q_{2} \\
q_{7} \\
q_{14} \\
p_{12}
\end{array}\right]
$$

\section{RESULTS AND DISCUSSION}

The left heart is modeled for ejection phase using Bond Graph unified modeling technique. The model is simulated using integro-differential equations and ode45. In this research paper the focus is only on Systolic Phase. For pressure volume relation, we have worked on the following integro-differential equation.

$\frac{1}{C_{2}(t)} \int Q l v d t-\frac{1}{C_{3}} \int Q l v d t=R_{1} Q l v+R_{2} Q l v+\frac{L D Q l v}{d t}$

Here, $\mathrm{Qlv}=\mathrm{q}_{7}$ (blood ejected by left ventricle)

$\int \dot{q}_{7} d t=u x$

$e_{l v} q_{7}(t)-\frac{1}{C_{3}} q_{7}(t)=R_{1} \frac{d}{d t} q_{7}+R_{2} \frac{d}{d t} q_{7}+\frac{L D}{d t} \dot{q}_{7}$

$\dot{q}_{7}=\frac{d}{d t} u(x)$

$d \frac{q_{7}}{d t}=\frac{d^{L}}{d t} u(x)$

Now Substituting,

$e_{l v}(t) u(x)-\frac{1}{C_{3}} u(x)=R_{1} \frac{d}{d t} u(x)+R_{2} \frac{d}{d L} u x+L \frac{d^{L}}{d t} u(x)$
Now solving this second order differential equation given the value of $\int \dot{q} d t=u(x)$; taking derivative of $\mathrm{u}(\mathrm{x})$ will provide the value of $\mathrm{Q}_{\mathrm{lv}}$. For plotting of aortic flow and left ventricular pressure we have used MATLAB ODE45. The results are compared with the most famous Wiggers diagram of Cardiac Cycle shown in Fig. 5. The Wiggers diagram physiologically indicates the time of systolic ejection, diastolic time, systolic max and minimum pressure. The end systolic and end diastolic volumes are also mentioned. The $\mathrm{X}$ axis is used to plot time, while $\mathrm{Y}$ axis is used to plot aortic pressure, ventricular pressure, atrial pressure, electrocardiogram, arterial flow and also heart sounds. This standard diagram helps us in the comparison and validation of results obtained from our model [16].

Fig. 6 explain the Left Ventricular Elastance Function E(t) taken in $\mathrm{mmHg} / \mathrm{ml}$, with respect to time in seconds. The significance of $\mathrm{E}(\mathrm{t})$ is already discussed in section 2.3. The ejection occurs at $0.32 \mathrm{sec}$. This value can be veified from Marwan, Chen work [1,15]. This factor is responsible for ventricular contraction.

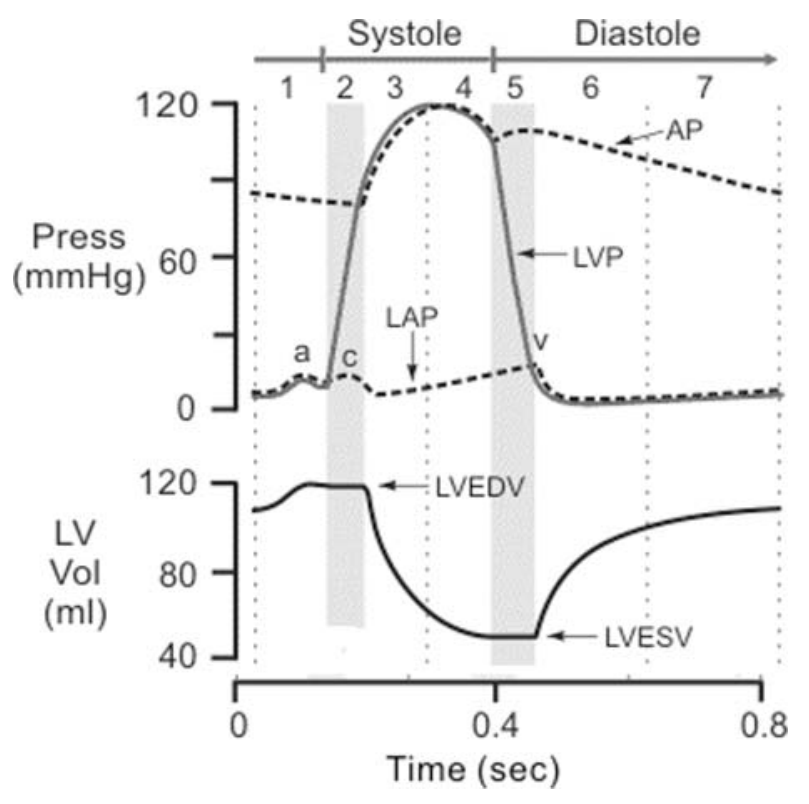

FIG. 5. WIGGERS DIAGRAM OF CARDIAC CYCLE [20] 
The Fig. 7 shows the pressure graph of the left ventricle during active systole or ejection phase. From our model simulation, the maximum value of the Left Ventricular Pressure LVP during systole comes out to be between $120-140 \mathrm{mmHg}$ at systolic time $\mathrm{t}=0.32$ seconds. The result ca also be verified from Simaan Marwan work [2]. It can also be observed in the Wiggers diagram [16], that the LVP is nearly $120 \mathrm{mmHg}$ at systolic time $\mathrm{t}=0.32 \mathrm{sec}$. Therefore this result is also verified.

The Fig. 8 shows the pressure and volume relationship of the Left Ventricle for the Systole phase. Note that this graph is only for Systolic or Ejection Phase. The maximum

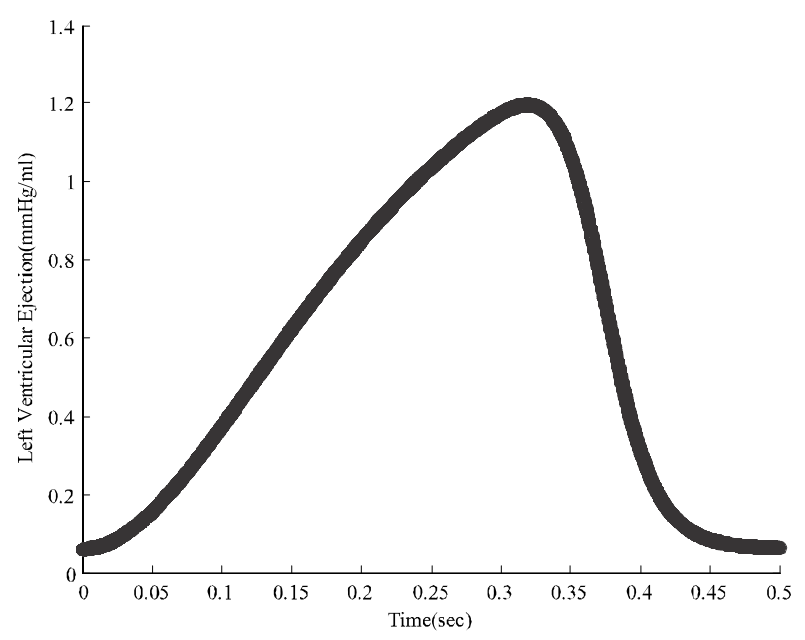

FIG. 6. LEFT VENTRICULAR ELASTANCE (MM HG/ML VS. TIME (SEC)

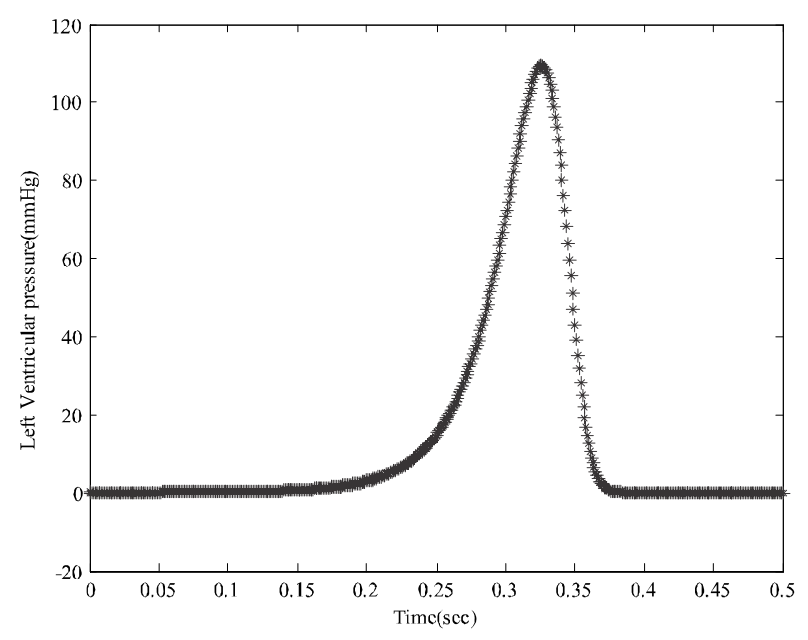

FIG. 7. LEFT VENTRICULAR PRESSURE VS. TIME left ventricular pressure is $120 \mathrm{mmHg}$ and the maximum volume is $70 \mathrm{ml}$. Thus the left ventricular pressure-volume relation obtained from model satisfy the physiological data present.

The Fig. 9 shows the outflow from left ventricle during Ejection or Systole.

The maximum aortic flow is $700 \mathrm{ml} / \mathrm{sec}$ and the systolic time is $0.32 \mathrm{sec}$. The graph clearly shows the time varying nature of ventricle outflow. As the time reaches the systolic time i.e. $\mathrm{t}=0.32 \mathrm{sec}$, the blood flow from ventricle is the highest value and then decreases with time hence entering into diastolic mode [5].

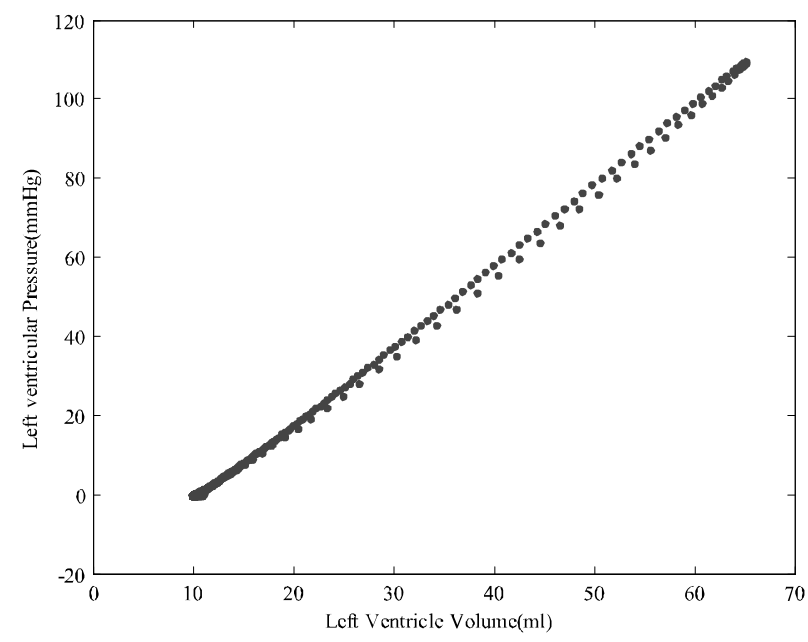

FIG, 8. LVP VERSUS LVV

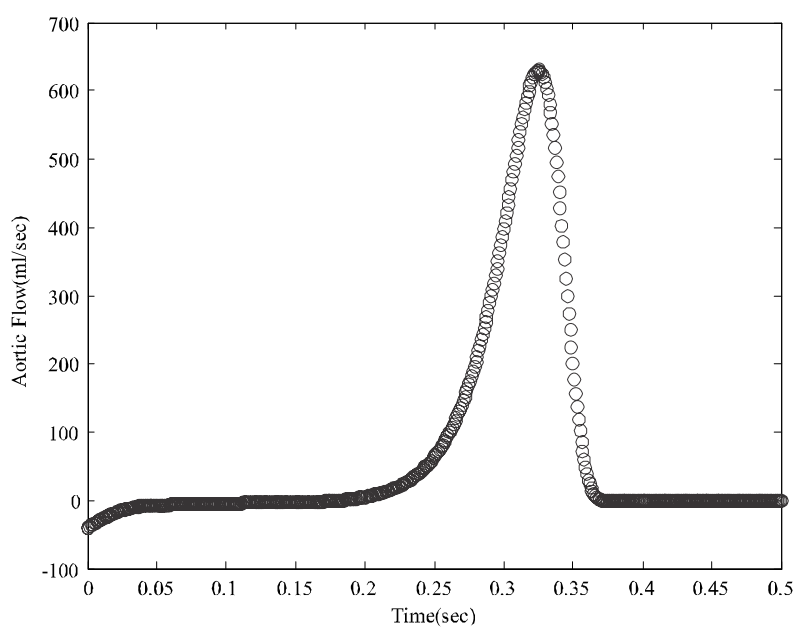

FIG. 9. TIME VERSUS AORTIC FLOW 


\section{CONCLUSION}

The simulation results obtained from Bond Graph shown above satisfy the Physiological data.The state space obtained from Bond Graph clearly indicates the contribution of each and every individual element much more clearly, for example, the contribution of the Systemic Compliance $\mathrm{C}_{3}$ is not clearly shown but in Bond Graph state space its contribution is quite prominent. Moreover, the Bond Graph approach is more attractive since one single formation can be used for all energy domains. The proposed model is a clarified depiction of the left ventricle portraying the anatomy of CVS deliberating the information between the physiologist and an engineer. Moreover, the essence of the segments of the model and the analogy in which they correspond is more apparent and simple using the Bond Graphical format. However, this model does not show the other phases such as Isovolumic or filling and is only limited to the systolic phase. In addition to this many chemical reactions are also not considered.

\section{ACKOWLEDGEMENTS}

The author is grateful to the contribution of Pakistan Navy College of Engineering, National University of Science and Technology, Islamabad, for providing the tools for modeling and simulation. The contribution of the faculty of Mehran University of Engineering and Technology, Jamshoro, and Hamdard University, Karachi, Pakistan, is also acknowledged.

\section{REFERENCES}

[1] Ferreira, A., Shaohui, C., David, G., Simman, M.A., and James, F., "A Dynamical State Space Representation and Performance Analysis of a Feedback Controlled Rotary Left Ventricular Assist Device", ASME Proceedings on Dynamic Systems and Control, pp. 617-626, [Doi:10.1115/IMECE2005-80973], 2005.

Simman, M.A., Antonio, F., Shaohi, C., James, F.A., and David, G., “A Dynamical State Space Representation and Performance Analysis of a Feedback-Controlled Rotary Left Ventricular Assist Device”, IEEE Transactions on Control Systems Technology, Volume 17, No. 1, pp. 15-28, [Doi:10.1109/TCST. 2008.912123,02], 2009.

[3] Rolle, V., "A Bond Graph Model of the Cardiovascular System", Acta Biotheoretica, Volume 53, No. 4, pp. 295-312, [Doi:10.1007/s10441-005-4881-4], 2005.
Wolfgang, B., "Bond Graph Methodology, Development and Analysis of Multidisciplinary Dynamic System Models", [e-ISBN 978-1-84882-882-7], Springer, 2010.

[5] Shao, H.C., "Baroreflex-Based Physiological Control of Left Ventricular Assist Device", Ph.D. Thesis, University of Pittsburgh, 2006.

[6] Suga, H.K., "Instantaneous Pressure Volume Relationships and their Ratio in the Excised, Supported Canine Left Ventricle", Circulation Research, American Heart Association, Volume 35, No. 1, pp. 117-126, [Doi:10.1161/01.RES.35.1.117,07], 1974.

[7] Chang, B.L., "Causality Assignment and Model approximation for Hybrid bond Graph: Fault Diagnosis Perspective", IEEE Transactions on Automation Science and Engineering, Volume 7, No. 3, pp. 570-580, [Doi:10.1109/TASE.2009.2026731], July, 2010.

[8] Liang, Z., Dhanjoo, N., Eddie, Y.K., Ngond Soo, T Lim., "Passive and Active Ventricular Elastance of the left Ventricle", Bio Medical Engineering, Volume 4, No.10, [Doi:10.1186/1475-925X-4-10], 2005.

[9] Wojcik, LA., "Modeling of musculoskeletal structure and function using a modular Bond Graph approach", Journal of the Franklin Institute, Volume 340, Number 1, pp. 63-76(14), [Doi: 10.1016/S0016-0032(03) 00011-5], January 2003.

[10] Hirayame, "Analysis of Systemic Circulation time varying Capacitance model of ventricle linked to electrical circuit of arterial tree", IEEE $22^{\text {nd }}$ International Conference, Volume 1, pp. 281 - 296, [Doi:10.1109/ IECON.1996.570966], 1996.

[11] Marwan, Simaan, A., "Rotary Heart Assist Devices", Springer Handbook of Automation, pp. 1409-1422, [Doi: 10.1007/978-3-540-78831-7], 2009.

[12] Diaz-Insua, M., Delgado, M., "Modeling and Simulation of the Human Cardiovascular System with Bond Graph; a Basic Development", Computers in Cardiology, IEEE, pp. 393-396, [Doi:10.1109/CIC.1996.542556].

[13] Linkens DA., Chen, HH, "The design of a Bond-Graphbased controller for muscle relaxant anesthesia", Proceedings IEEE International Conference on Systems Man and Cybernetics: Intelligent Systems for the 21st Century; Vancouver, BC, Vol. 4, pp. 3005-3010, [Doi: 10.1109/ICSMC.1995.538242], 1995.

[14] C.O. Olsen, G.S. Tyson Jr., G.W. Maier, J.A. Spratt, J.W. Davis, J.S. Rankin, "Dynamic ventricular interaction in the conscious dog", Circ. Res., 52, pp. 85-104,[Do:10.1161/01.RES.52.1.85],1983.

[15] Marwan, Simaan,A., "Modeling and control of the heart left ventricle supported with a rotary assist device", $47^{\text {th }}$ IEEE Conference on Decision and Control, [Doi:10.1109/CDC.2008.4739226], 2008.

[16] Mitchell, Janie, R., Wang, Jiun, Jr., “Expanding application of the Wiggers diagram to teach cardiovascular physiology", Advanced Physiology Education, 38(2):170-5. [Doi:10.1152/advan. 00123.2013], June 2014. 